\title{
Erratum to: Alcohol dehydrogenase gene ADH3 activates glucose alcoholic fermentation in genetically engineered Dekkera bruxellensis yeast
}

\author{
Anna Judith Schifferdecker ${ }^{1}$ - Juozas Siurkus ${ }^{2}$. Mikael Rørdam Andersen ${ }^{2}$. \\ Dorte Joerck-Ramberg ${ }^{2} \cdot$ Zhihao Ling $^{1} \cdot$ Nerve Zhou $^{1}$ - James E. Blevins ${ }^{3}$. \\ Andriy A. Sibirny ${ }^{4,5}$. Jure Piškur ${ }^{1}$. Olena P. Ishchuk ${ }^{1}$
}

Published online: 6 February 2016

(C) Springer-Verlag Berlin Heidelberg 2016

Erratum to: Appl Microbiol Biotechnol

DOI 10.1007/s00253-015-7266-x

The original version of this article inadvertently contained mistake in the author list. See below:

Incorrect: Juozas Siurkas

Correction: Juozas Siurkus

The online version of the original article can be found at http://dx.doi.org/ $10.1007 / \mathrm{s} 00253-015-7266-\mathrm{x}$.

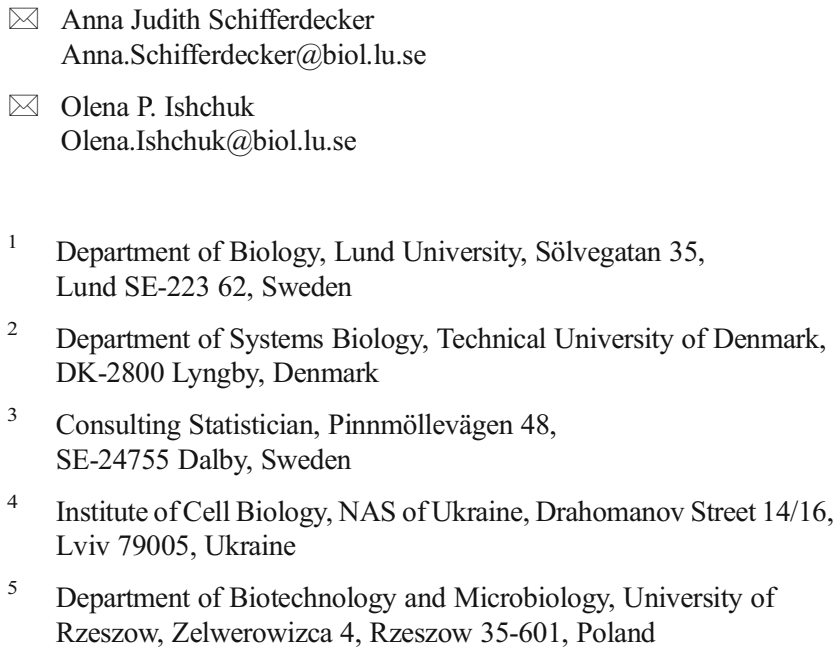

1 Department of Biology, Lund University, Sölvegatan 35, Lund SE-223 62, Sweden

2 Department of Systems Biology, Technical University of Denmark, DK-2800 Lyngby, Denmark

3 Consulting Statistician, Pinnmöllevägen 48, SE-24755 Dalby, Sweden

4 Institute of Cell Biology, NAS of Ukraine, Drahomanov Street 14/16, Lviv 79005, Ukraine

5 Department of Biotechnology and Microbiology, University of Rzeszow, Zelwerowizca 4, Rzeszow 35-601, Poland 